\title{
Moral distress: an inevitable part of neonatal and paediatric intensive care?
}

\author{
David Field, ${ }^{1}$ Jenna Deeming, ${ }^{2}$ Lucy K Smith ${ }^{1}$
}

The paper by Prentice et $a l^{1}$ reports a systematic review of moral distress occurring in neonatal and paediatric intensive care units. This term, which may be unfamiliar to many readers, has been defined as the anguish experienced when a health professional makes a clear moral judgement about what action he/she should take but is unable to act accordingly due to constraints (societal, institutional or contextual). ${ }^{2}$ In a situation of moral distress, the health professional can see, from their point of view, that there is an ethically correct action but is powerless to act, a situation that will be familiar to all those who work in neonatal or paediatric intensive care teams.

Moral distress is not a new phenomenon, although the scenarios where it arises may have changed due to developments in society's beliefs and the healthcare system and dramatic improvements in technology. Perhaps the most clear UK example of how the views of society at large have changed in this context over time comes from the trial of Dr Leonard Arthur (https://en.wikipedia.org/wiki/Leonard_ Arthur; accessed 21 March 2016). In 1981, Dr Arthur, a paediatrician based in the English Midlands, was tried for attempted murder following the death of a newborn baby with Down's syndrome whom he had prescribed 'nursing care only' and sedatives. At Dr Arthur's trial, the president of the London College of Physicians gave evidence in which he said, "I say that it is ethical, in the case of a child suffering from Down's, and with a parental wish that it should not survive, to terminate life providing other considerations are taken into account such as the status and ability of the parents to cope in a way that the child could otherwise have had a happy life". Dr Arthur was found not guilty, but such a course of management now would be seen as

${ }^{1}$ The Infant Mortality and Morbidity Studies Group (TIMMS), Department of Health Sciences, University of Leicester, Centre for Medicine, Leicester, UK; ${ }^{2}$ Neonatal Unit, University Hospitals of Leicester NHS Trust, Leicester Royal Infirmary, Leicester, UK

Correspondence to Dr Lucy K Smith, The Infant Mortality and Morbidity Studies Group (TIMMS), Department of Health Sciences, University of Leicester, Centre for Medicine, University Road, Leicester LE1 7RH, UK; lucy.smith@le.ac.uk wholly unacceptable. Since that time, society's attitudes and the medical management of children with Down's syndrome with major congenital anomalies changed. Whereas previously such children were not offered intensive care, it gradually became routine.

Today, similar discussions arise in relation to the extent of support that should be given to children with trisomy 18 or trisomy 13 as well as babies with a wide variety of very major congenital anomalies and/or genetic disorders for whom treatment may well prolong survival but not cure. For some of these conditions, there is the prospect that with time improvements in care will offer future children similarly affected a more regular chance of good outcomes that are currently not possible (eg, hypoplastic left heart syndrome). However, for other anomalies, such as the most severe forms of bladder extrophy, only palliation and longer-term survival can be achieved.

Similarly, issues of moral distress arise around the treatment of babies born at the limits of viability. Throughout the time that specialist neonatal care has been available, there has always been a 'limit of viability'. The difference in the last few years is that it seems that outcomes for the most immature babies have plateaued both in terms of survival and morbidity. ${ }^{3}$ For some babies, there may well be a trade-off in terms of death or survival with significant long-term morbidity. It is this group that is likely to be one source of ongoing moral distress, especially as in the absence of some very significant new technology or approach to management, this group of babies is likely to remain associated with very high rates of mortality and morbidity. While we reflect that the decisions to treat those born at or below 28 weeks gestation in the 1970s led to the improved knowledge and over time better outcomes for these children, the same potential for incremental improvements has not been replicated in those born before 23 weeks. Despite the presence of widely accepted guidelines from around the world regarding the conservative management of these babies, there are nonetheless reports of the occasional, apparently, miraculous survivor at below 23 weeks of gestation that is widely publicised.
Prentice et $a l^{1}$ highlight that the term moral distress has been used most often in relation to nurses experiencing distress while carrying out management decisions made by doctors, typically, to continue with active and, sometimes, aggressive support that the nurse feels is either futile or overly burdensome. The studies identified in the report were focused very much on this interaction. In contrast, while they did identify studies that reported doctors' views, here the same situations were largely considered 'ethical dilemmas', where there were two or more possible courses of action, but with a downside to each. This distinction between different healthcare professionals' experience of moral distress is also likely to be changing over time.

Clearly in the present era, parents rightly have a great influence in the management of their child. However, evidence from mainly the lay media highlights that, unsurprisingly, their views and choices vary enormously when confronted with decisions about their critically ill child for whom intact survival seems a remote possibility. The majority of difficult decisions relating to care provision are reached in consensus with the family and, where appropriate, the child. However, moral distress does arise in cases where there is significant disagreement between the healthcare professional(s) and the family regarding what is in the child's best interests. As highlighted by Larcher $e t a l^{4}$ in their framework for practice regarding withdrawing or withholding treatment, "such disagreement may be borne of miscommunication or differences in genuine and deeply held beliefs". In a detailed discussion of their findings, Prentice et al point out that studies involving the views of parents in this context are generally lacking, although they do identify that decisions to continue aggressive support when a reorientation of care seems appropriate are often made in deference to parents' wishes.

In relation to heathcare professionals, Prentice et al indicated that most studies identified no relationship between characteristics such as age, religion, level of education and marital status and the experience of moral distress. However, it seems highly unlikely that the same is entirely true of parents. Of course, healthcare professionals do differ in how they feel particular life and death situations should be managed. It is suggested that this is the result of differences in experience or knowledge as it is a concern regarding the long-term impact of aggressive attempts to sustain life that seems to be a particular focus of moral distress for staff. This is obviously not a simple issue, 
and almost certainly wider opinions and beliefs will influence individuals' reactions to a particular situation. ${ }^{5-7}$

With each incremental technological advance, there is the potential for moral distress to occur on a steadily increasing basis. This is an issue that cannot be dealt with by intensive care units alone. There are important questions for society at large such as when, if ever, is a life not worth living? In the absence of a more general view on how to approach such cases, individual teams will 'do their best', reaching their own conclusions with parents and hence perpetuating the inevitable widespread variation in practice that exists now. However, an equally important question for society is if life is always worth preserving then families should expect to receive the support they need as the child grows in order to ensure that the burden of caring for a severely disabled child is shared and similarly appropriate care in adult life can be assured. With changes in societal beliefs, advances in technology and the increase in provision of care by multidisciplinary teams in which "each member has their own ethical opinions regarding health, treatment options, autonomy and the value placed on life", 8 moral distress is inevitable. Its elimination is unlikely to be possible or appropriate, but by recognising its presence, identifying scenarios where staff feel powerless or where they feel that they are jeopardising their moral integrity, we can start to address moral distress.

Funding LKS is funded by a National Institute for Health Research Career Development Fellowship. This article presents independent research funded by the National Institute for Health Research (NIHR).

Disclaimer The views expressed are those of the authors and not necessarily those of the National Health Service, the NIHR or the Department of Health.

Competing interests None declared.

Provenance and peer review Commissioned; internally peer reviewed.

To cite Field D, Deeming J, Smith LK. Arch Dis Child 2016;101:686-687.

Published Online First 23 June 2016

\section{Sinked}

http://dx.doi.org/10.1136/archdischild-2015-309410
Arch Dis Child 2016;101:686-687. doi:10.1136/archdischild-2015-310268

\section{REFERENCES}

1 Prentice T, Janvier A, Gillam L, et al. Moral distress within neonatal and paediatric intensive care units: a systematic review. Arch Dis Child 2016;101:701-8.

2 Jameton A. Nursing practice: the ethical issues. Englewood Cliffs, NJ: Prentice-Hall, 1984.

3 Costeloe KL, Hennessy EM, Haider S, et al. Short term outcomes after extreme preterm birth in England: comparison of two birth cohorts in 1995 and 2006 (the EPICure studies). BMJ 2012;345:e7976.

4 Larcher V, Craig F, Bhogal $\mathrm{K}$, et al. Making decisions to limit treatment in life-limiting and life-threatening conditions in children: a framework for practice. Arch Dis Child 2015;100:s1-23.

5 Roy R, Aladangady N, Costeloe K, et al. Decision making and modes of death in a tertiary neonatal unit. Arch Dis Child Fetal Neonatal Ed 2004;89: F527-30.

6 Ahmed S, Arasu A. Another ethical dilemma in neonatology. Arch Dis Child Fetal Neonatal Ed 2011;96:A72.

7 Lam HS, Wong SP, Liu FY, et al. Attitudes toward neonatal intensive care treatment of preterm infants with a high risk of developing long-term disabilities. Pediatrics 2009;123:1501-8.

8 Janvier $A$, Nadeau $S$, Deschênes $M$, et al. Moral distress in the neonatal intensive care unit: caregiver's experience. J Perinatol 2007;27:203-8. 